Mirla Villadiego Prins*

\title{
GANANCIAS DE LA PUBLICIDAD, PÉRDIDAS DE LA ESCUELA ¿Hacia dónde apunta la socialización de las prácticas y los relatos dominantes en la sociedad contemporánea?**
}

\begin{abstract}
Resumen
La pregunta problema de la cual parte este artículo es por qué o de qué manera la socialización de las prácticas de consumo está haciendo que el relato publicitario sea cada vez más significativo para la sociedad contemporánea, que el relato ilustrado, socializado en las prácticas de enseñanza de la escuela. Una aproximación a esta inquietud lleva a suponer que esto ocurre porque existe una gran coherencia entre la prefiguración, desprevenida o inconsciente, de los fines e intereses que la sociedad hace en sus prácticas de consumo y la reincorporación de ese inconciente colectivo en el diseño u ordenamiento, conciente, que la industria publicitaria realiza de sus relatos para poder garantizar la aceptación social. Finalmente, la conclusión es que si bien es cierto que desde esta hipótesis se puede explicar el éxito del relato publicitario, también lo es que desde ella misma también es posible entender el cansancio del relato ilustrado de la escuela.
\end{abstract}

Palabras clave. Relato publicitario, socialización, relato ilustrado, escuela, educación.

\section{Abstract}

The problem question which starting from this paper is why or of what mode the socialization of the consumption practices is making that publicity statement to be every time more significant for the contemporary society, than the illustrated statement, socialized in the teaching practices of the school.

An approach to this query get to suppose that this happens because a great coherence exist among the prefiguration, unprepared or unconscious, of the proposes and interests that the society made in their consumption practices and the reincorporation of this collective unconscious in the design or ordering, conscience, that the publicity industry carried out of her statements to be able to guarantee the social acceptance.

Finally, the conclusion is that although it is certain that from this hypothesis can to be explained the success of the publicity statement, also it is that from herself is possible to understand the fatigue of the illustrated statement of the school.

Key words. Publicity statement, socialization, illustrated statement, school, education.

.. Magíster en Comunicación. Profesora Universidad Javeriana y Universidad Jorge Tadeo Lozano. E.mail: mvilla@javeriana.edu.co Este artículo fue recibido el 19 de septiembre de 2003 y aprobado el 31 de octubre de 2003. 
Frecuentemente, el concepto de socialización suele asociarse a las prácticas pedagógicas desplegadas en la escuela, con el propósito de ejercer un control ideológico, de evitar las desviaciones de la conducta individual y colectiva del orden social y políticamente establecido o de orientar el destino de las diferentes colectividades hacia la consecución de unas mejores condiciones materiales y espirituales de existencia.

Desde esta perspectiva, el relato ilustrado que sustentan las prácticas de enseñanza de la escuela, es investido no sólo de una gran legitimidad, sino también de un gran prestigio en el sentido en que se le considera como un instrumento determinante a la hora de conducir, de manera deseable, el pensamiento y la acción de la sociedad.

Sin embargo, en un sentido más amplio del término y tal como es entendido en la perspectiva sociológica, el concepto de socialización remite a la reflexión sobre una infinidad de prácticas que atraviesan mucho más radicalmente a la sociedad de hoy que la misma enseñanza impartida en las aulas escolares.

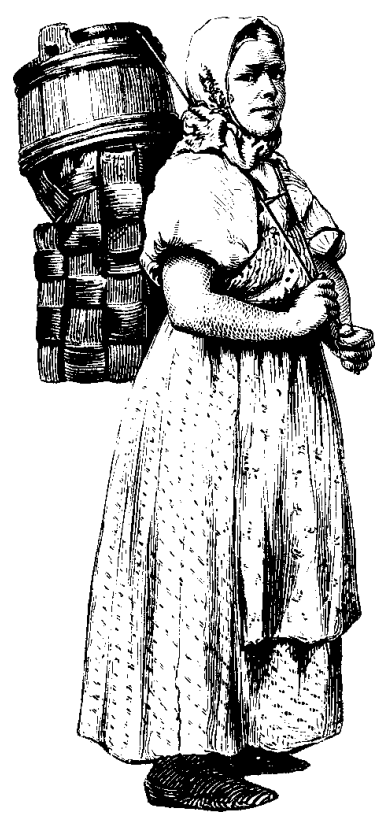

Un caso sintomático de esta situación lo constituyen las prácticas de consumo, las cuales no pueden seguir siendo consideradas como la consecuencia de la seducción o el poder que el relato publicitario despliega sobre la sociedad, porque este relato por sí solo no tiene la capacidad para generar estímulos tan poderosos y capaces de incidir en los deseos y necesidades que incitan dichas prácticas, sino que estos deseos y necesidades también son el resultado de un conjunto de condiciones de orden político, económico, cultural y hasta tecnológico, generadas al interior de nuestro contexto histórico.

Deja dicho esto que la socialización de las prácticas de consumo resulta ser un fenómeno muy complejo, que no puede entenderse como el resultado del ejercicio de la voluntad del anunciante o del publicista a partir de la manifestación de sus relatos, sino que se precisa considerar lo que un sociólogo, como Georg Simmel, denomina como acción recíproca, esto es, una situación en la que el destino de una sociedad no está determinado por ninguna voluntad particular sino que, a consecuencia de la permanente relación social o de la coexistencia aislada de cada individuo, ese destino es el resultado de la suma de acciones individuales que pueden imprimir tendencias al rumbo social y a través de las cuales se pueden explicar la complicidad o la resistencia de ciertos grupos con el poder.

Desde este punto de vista, estas apreciaciones supondrían plantearse preguntas o problemas desde las cuales sea posible explicar el modo como funciona la socialización de las prácticas de consumo sobre el relato publicitario y no, como hasta entonces se ha hecho, en el sentido de pensar que es el relato publicitario el que determina la socialización de las prácticas de consumo.

Más concretamente y para efectos de los propósitos que alientan la realización de este artículo, la pregunta problema de la cual se parte es por qué o de qué manera la socialización de las prácticas de consumo está haciendo que el relato publicitario sea cada vez más significativo para la sociedad contemporánea, que el relato ilustrado, socializado en las prácticas de enseñanza de la escuela. Una aproximación a esta inquietud lleva a suponer que esto ocurre porque existe una gran coherencia entre la prefiguración, desprevenida o inconsciente, de los fines e intereses que la sociedad hace en sus prácticas de consumo y la reincorporación de ese inconsciente colectivo en el diseño u ordenamiento, conciente, que la industria publicitaria realiza de sus relatos para poder garantizar la aceptación social.

Para lograr esto, serán expuestas algunas consideraciones sobre: la estigmatización del relato publicitario, que ha impedido una aproximación mucho más comprensiva al problema de la socialización de las prácticas del consumo; la estructura significativa del relato publicitario; algunas precisiones sobre el concepto de socialización; un recorrido por los análisis hechos a la socialización de las prácticas del consumo partiendo de lo que se suponen son las determinaciones del relato publicitario, un análisis de la socialización de las prácticas del consumo pensado en la incidencia del contexto histórico, un balance sobre las ganancias de la publicidad y las pérdidas de la escuela y finalmente, unas conclusiones que explican no sólo el éxito del relato publicitario sino también el cansancio del relato ilustrado de la escuela.

\section{La estigmatización del relato publicitario}

Varias marcas negativas tienden a deslegitimar o ignorar la importancia que el relato publicitario tiene para la sociedad contemporánea, así como también a reducir la necesidad de abordar un estudio siste- 


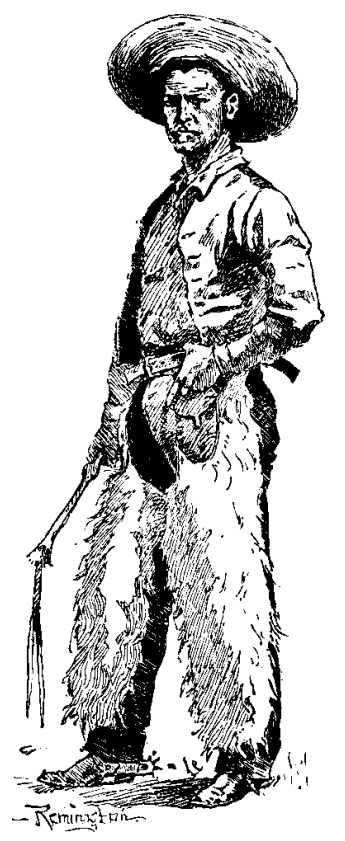

mático de las funciones que este relato cumple en el complejo juego de la socialización moderna. La primera de ellas parte del presupuesto de que su función, única y exclusiva, es la de procurar la venta de mercancías, favoreciendo con ello la producción y reproducción del capital.

La segunda, asume que, siendo la venta su función primaria, los planteamientos del relato publicitario estarían desligados de las grandes preocupaciones e intereses de la sociedad. El relato publicitario estaría vaciado del sentido social trascendente y por lo tanto no sería más que una expresión gratuita y banal, cuyo propósito estaría reducido a dar a conocer los atributos de las mercancías que promociona.

La tercera estigmatización se deriva de la idea de que el relato surte un efecto poderoso sobre la sociedad que podría ser observado no sólo en la inducción a la compra, sino también en el encuadramiento de la conciencia individual y colectiva dentro de los límites ideológicos de este relato. No en vano se explica entonces que se acuñe un concepto como el de sociedad de consumo y que se lo examine desde la alineación que producen las estructuras significativas del bienestar y del hedonismo que subyacen en ese relato.

Finalmente, el cuarto estigma se asocia con la idea de que el relato publicitario sería una especie de producto de lo que algunos investigadores, todavía muy emparentados con las premisas del análisis conductista, denominan como "fábrica de deseos" (Ramonet, 2002: 22) o lo que en otros términos podríamos entender como la industria publicitaria que, desde este punto de vista, no podría expresarse más que en términos del sentimentalismo y la emoción.

\section{La estructura significativa del relato publicitario}

No existe una idea precisa para definir el concepto de estructura significativa, pero puede deducirse de la comprensión que de ella han hecho algunos autores (Paoli, 1980: 55) que se trata de la racionalidad y la expresividad que subyace a los discursos dominantes de una sociedad. En el caso del relato publicitario, la racionalidad que lo subyace asume la forma de dos promesas que pueden ser nombradas como las promesas del bienestar y las promesas del hedonismo.

La condición que, según este relato, hace concreta esas promesas es seguir las indicaciones de la moda, esto es, las indicaciones de renovar permanentemente aquello que es consumido, independientemente de su daño o de su desgaste, llevando de esta manera a asociar el consumo material con el consumo simbólico, en el que no sólo se consumen mercancías sino también los signos del estatus social y en el que esos signos se ven reflejados más o menos en las posibilidades de seguir el ritmo que el relato publicitario impone, supuestamente, a los consumos.

Consecuentemente con esto y con el propósito de examinar estas cuestiones en términos históricos, puede afirmarse que, nacido en el contexto de la sociedad moderna e industrializada, el relato de la publicidad comercial alude fundamentalmente a la promesa del bienestar. En medio del proceso de evolución de la técnica que permitía ampliar no sólo los niveles de producción sino también los de consumo, el relato publicitario hizo una traducción de las demandas espirituales y materiales en términos de la oferta de las mercancías disponibles en el mercado.

Sus retos eran por una parte sacar al consumo de bienes y servicios de los restringidos límites de la supervivencia o de lo estrictamente necesario para la vida, como hasta entonces lo había impuesto la moral puritana y la llamada "Ley de bronce" hasta el comienzo de la gran depresión del año de 1929 (Cueto, 1985:16) y según la cual el criterio para definir el salario del obrero era simplemente el de garantizar su supervivencia. Por otra parte, el otro reto era el de legitimar una nueva racionalidad en donde las compras no dependieran del ritmo lento del desgaste de los productos consumidos sino de la voluntad de distinguirse o de disfrutar del bienestar.

Desde entonces, la estrategia del relato publicitario ha sido la de anticipar en su diseño, las respuestas a las expectativas de su target, por eso el relato publicitario nunca ha sido una jerga vacía, gratuita o interesada únicamente en la comercialización. De eso puede dar cuenta el hecho de que ante las precariedades de la existencia en el naciente modo de producción industrial y ante las angustias y las incertidumbres de una sociedad, también recientemente secularizada, la respuesta del relato publicitario fuera la promesa del bienestar aquí y ahora, mediante el consumo de mercancías que ese relato publicitario promocionaba.

Los términos mediante los cuales se expresa el relato publicitario del 
bienestar tienen que ver entonces con la abundancia, la disponibilidad, la utilidad, el confort, la facilidad, la calidez, la belleza, la bondad de los bienes y servicios ofrecidos para felicidad y la tranquilidad de quienes los consumen.

El relato publicitario convierte al bienestar en un valor no sólo culturalmente aceptable sino también socialmente deseable para elevar el nivel de calidad de vida. Sin duda alguna, este hecho cambia el estatuto político e ideológico del consumo, en el sentido en que desde entonces dejaría de ser considerado como una manifestación de la vanidad o la banalidad de las clases sociales privilegiadas, para convertirse en uno de los termómetros del desarrollo y de la justicia social.

A otro nivel puede identificarse el relato publicitario del hedonismo. El contexto en el que surge este relato es el de las sociedades de más alto desarrollo económico en donde la producción industrial ha dejado de ser altamente estandarizada para dar paso, mediante su flexibilización, a una oferta de bienes y servicios más amplia y más diversa. Sin embargo, debe aclararse que este relato no es exclusivo de las sociedades con ese grado de desarrollo económico, puesto que a consecuencia de las tendencias globalizadoras de la publicidad, dicho relato, ha logrado traspasar fronteras y difundirse hasta las regiones con menor dinamismo económico (Mattelart, 2003).

Las transformaciones de las condiciones materiales y espirituales de estas sociedades globalizadas hacen que el diseño del relato, aunque siga funcionando bajo la misma racionalidad del consumo que había inaugurado el relato publicitario del bienestar, deba ser planteado en otros términos. El motivo es fundamentalmente que estas sociedades han resuelto muchas de las necesidades que existían en el contexto de la sociedad industrial y gracias a sus altos niveles de creci-

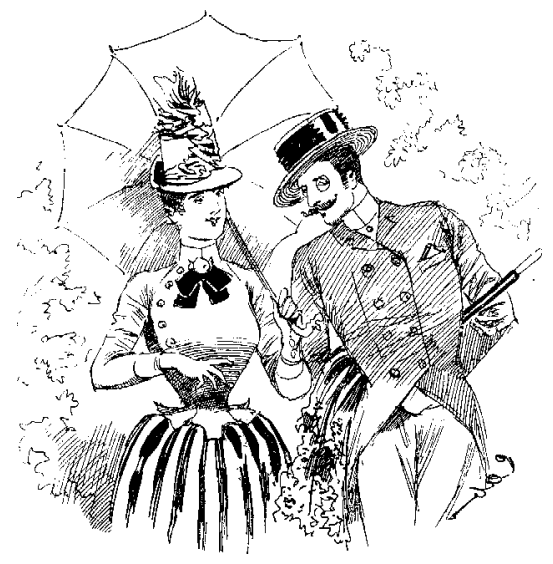

Esta relajación del relato, no da razones para pensar que se haya convertido en algo gratuito; de hecho, como también lo ha señalado Eguizábal, esta situación respondería, en el caso del relato que se expresa mediante el código del humor, a una crisis de los formalismos y los convencionalismos, abriendo paso a "lo cordial, campechano y espontáneo" (Eguizábal, 1991: 36) y su propósito sería el de generar proximidad con la cotidianidad de sus destinatarios, mientras que el uso del código fantástico estaría relacionado con las posibilidades que el desarrollo tecnológico ha traído para la narración de ficción y su propósito sería el de impresionar a los consumidores por la vía de la espectacularización.

perar las condiciones de precariedad de la existencia, instaurando de este modo, el reinado del hedonismo o la búsqueda de la satisfacción $y$ el placer en los derroches del mundo del consumo.

La función del relato publicitario del hedonismo no es la de predicar más las bondades, utilidades y bellezas que los consumidores esperaban encontrar en los productos que compraban, tal como ocurre con el relato publicitario del bienestar. Lo que se pretende con esta nueva versión del relato publicitario es facilitar la elección de los consumidores en medio de la jungla de marcas disponibles en el mercado.

De ahí que pueda explicarse entonces cierta despreocupación por el sentido y un afán mucho más fuerte de lograr llamar la atención y de posicionarse en la mente de los consumidores con un lenguaje sencillo, expresado en unos códigos fantásticos o humorísticos, como bien lo ha señalado Raul Eguizábal y según lo cual "ciertos mensajes publicitarios parecen un puro juego de palabras, un ejercicio aleatorio de signos superficiales que nos vuelven al placer de los juegos de palabras infantiles, al efecto de ciertas drogas estimulantes que provocan risas gratuitas, fantasías irracionales y el humor absurdo" (Eguizábal, 1991: 31).
De alguna manera, este adelgazamiento y esta fluidez del relato publicitario del hedonismo también estaría encaminado a funcionar bajo lo que Lipovetsky considera como el principio rector de la sociedad hedonista: la seducción (Lipovetsky, 2000: 17). Bajo este principio no habría, sin embargo, imposición de los consumos sino una ligera orientación de los gustos hacia la búsqueda del placer.

\section{Algunas precisiones sobre el concepto de socialización}

Realmente, no han sido pocas las referencias que se han escrito sobre el concepto de socialización en las ciencias sociales, pero ha sido el gran sociólogo alemán, Georg Simmel, quien ha aportado las, tal vez, más importantes claves para poder comprender ese concepto en la sociedad contemporánea.

Para Simmel, la socialización no es sólo el más preciado objeto de la investigación sociológica, sino sobre todo una abstracción que esa disciplina construye para poder entender el desarrollo histórico de la sociedad. Para este autor "ya no es posible explicar por medio del individuo, de su entendimiento y de sus intereses, los hechos históricos (en 
el sentido más amplio de la palabra), los contenidos de la cultura, las formas de las ciencias, las normas de la moralidad; y si esta explicación no basta, recurrir enseguida a causas metafísicas o mágicas... hoy creemos comprender los fenómenos históricos por las acciones recíprocas y conjuntas de los individuos, por la suma y sublimación de incontables contribuciones individuales, por la encarnación de las energías sociales en entidades que están más allá del individuo y que desarrolla por encima de él" (Simmel, 1997: 13).

Puede deducirse entonces, de las consideraciones de Simmel, que el desarrollo histórico de la sociedad no depende ni de un poder, cuya voluntad imprima una dirección al destino social, ni tampoco de las fuerzas ciegas del azar, sino que por el contrario, ese desarrollo está condicionado por una serie de fuerzas, formas y contenidos que asuma la relación social en el proceso de socialización y dentro de unos contextos sociales, políticos y culturales muy específicos.

En esencia, para este autor, lo que funda a la sociedad es la acción recíproca, en la que los individuos influencian y a la vez son influenciados por los demás individuos con los cuales comparten su existencia. Según Simmel, "esta acción recíproca se produce siempre por determinados instintos o por determinados fines. Instintos eróticos, religiosos

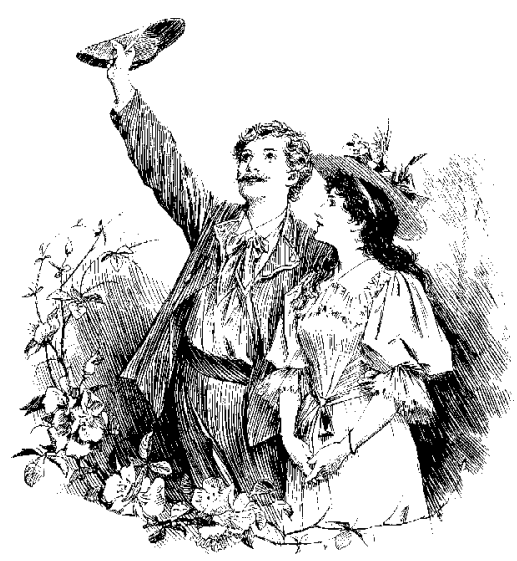

o simplemente sociales; fines de defensa o de ataque, de juego o de adquisición, de ayuda o de enseñanza... la existencia de aquellos instintos y de aquellos fines que movieron a unirse, se han convertido en una unidad, es decir en una sociedad" (Simmel, 1997: 16).

Esa unidad es lo que el sociólogo alemán comprende como socialización. Sin embargo, no se trata de una unidad en la que las acciones o las prácticas se manifiesten bajo una sola expresión; de hecho, lo que sostiene Simmel es que esta unidad, que sólo puede ser pensada como tal en el sentido de la orientación o de la tendencia que la acción recíproca le imprima al desarrollo social, está constituida por una heterogeneidad de acciones y situaciones, como por diversos grados de intensidad de la relación social, que pueden ir "desde la unión efímera para dar un paseo, hasta la constitución de la familia, desde las relaciones a plazo, hasta la pertenencia a un Estado, desde la convivencia fugitiva en un hotel, hasta la unión estrecha que significaban los gremios medievales" (Simmel, 1997: 16).

Según Simmel, lo que da existencia a la sociedad son las diversas clases de acción recíproca y no la acción independiente de cada individuo; por el contrario para él, "la socialización sólo se presenta cuando la coexistencia aislada de los individuos adopta formas determinadas de cooperación y colaboración que caen bajo el concepto general de acción recíproca (por consiguiente, la socialización es la forma de diversas maneras realizada, en la que los individuos, sobre la base de intereses sensuales o ideales, momentáneos o duraderos, concientes o inconscientes que impulsan causalmente o inducen teleológicamente, constituyen una unidad dentro de la cual se realizan aquellos intereses)" (Simmel, 1997: 17).

De las consideraciones hechas por Simmel acerca de la socialización, puede deducirse entonces, que la condición esencial para que esa unidad, esa orientación o esa tendencia tenga lugar en una dirección determinada es preciso que estén esbozados, de alguna manera, los fines, los intereses y los instintos de la sociedad en las prácticas o acciones que desarrolla cotidianamente; por eso, no es descabellado pensar que en las prácticas de consumo de la sociedad contemporánea estén prefigurados esos intereses y que el éxito del relato publicitario obedezca a su capacidad para recoger esos intereses, esbozados de manera inconciente en las prácticas, ordenarlos, rediseñarlos, darle una forma que los haga concientes y atractivos para una sociedad.

\section{Antitesis: las determinaciones del relato publicitario sobre las prácticas de consumo}

La interpretación dominante sobre los procesos de socialización llevados a cabo en la llamada sociedad de consumo, asume que los relatos publicitarios determinan las prácticas de consumo, pues se asume que esta socialización es impuesta por quienes tienen el poder, mientras que del otro lado, el de los consumidores, sólo hay lugar para el ejercicio pasivo del consumo. De ahí que al relato publicitario se le defina como una herramienta para la promoción y venta de mercancías, pero también como un dispositivo para el control ideológico de la sociedad.

No en otro sentido podría entenderse que el relato publicitario tendría como misión lograr el moldeamiento o encuadramiento de la conciencia social e individual, dentro de los límites ideológicos que el capitalismo ha trazado e impuesto a la sociedad de consumo y desde donde se impondría, cada vez más, la reducción del ciclo entre producción y consumo, para lograr que la sociedad busque consumir más.

Una elaboración conceptual en esta línea se encuentra magistralmente 
expuesta en las consideraciones que algunos integrantes de la Escuela de Frankfurt hicieron en la Teoría Crítica. De ello da buena cuenta el conocido ensayo de Theodor W. Adordo y Max Horkheimer sobre la industria cultural, en donde pueden identificarse dos claves explicativas para entender el modo en que la industria cultural (en este caso particular la publicidad) imprime a los procesos sociales una orientación funcional a los intereses del capitalismo post-industrial. La primera de esas claves tiene que ver con la constitución objetiva de los productos culturales y la segunda, con las modalidades de consumo que en virtud de esa constitución objetiva se imponen a los destinatarios de dichos productos.

Con respecto a la constitución objetiva de los productos culturales, asumen que en ellos todas las manifestaciones de la cultura se traducen en el lenguaje del entretenimiento. No se observa en el diseño de estos productos el propósito de alcanzar la originalidad o el estilo porque la industria cultural ha consagrado como principio fundacional la imitación o la reproducción perpetua. En la industria cultural no habría, entonces, espacio para lo novedoso sino apenas para una pequeña modificación de los detalles, que permite dar la impresión de que los contenidos de estos productos han sido renovados y que en el interior de la industria circula una oferta cultural muy diversa.

En relación con las modalidades de consumo sostienen que esta constitución de los productos "no deja a la fantasía ni al pensar de los espectadores dimensión alguna en la que puedan moverse por su propia cuenta sin perder el hilo, con lo que se adiestra a sus propias víctimas para identificarlo inmediatamente con la realidad. La atrofia de la imaginación y la espontaneidad del consumidor cultural contemporáneo no tiene necesidad de ser manejada según mecanismos psicológicos. Los productos mismos a partir del

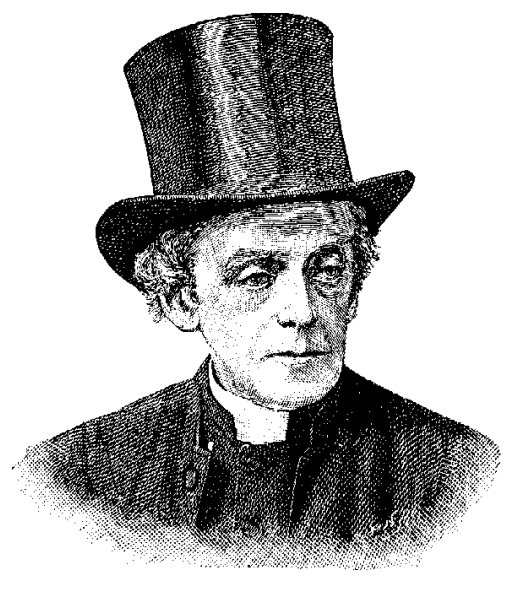

Siguiendo por esta línea de análisis puede decirse que, siendo un producto más de la industria cultura, el relato publicitario no escaparía a su racionalidad. Desde este punto de vista, ni la estructura, ni el funcionamiento del relato publicitario se producirían de manera espontánea o azarosa sino todo lo contrario, plenamente ajustadas a las necesidades de un capitalismo que en aras de su crecimiento sin límites, asume el control de todos los ámbitos de la cultura, incluso el de los que parezcan más insignificantes para ella, como en el caso del relato publicitario.

más típico, el film sonoro, paralizan tales facultades mediante su misma constitución objetiva. Tales productos están hechos en forma tal que su percepción adecuada exige rapidez de intuición, dotes de observación, competencia específica, pero prohíbe también la actividad mental del espectador, si este no quiere perder los hechos que pasan rápidamente delante" (Adorno y Horkheimer, 1992:184).

Bajo estas circunstancias, cualquier búsqueda, cualquier iniciativa del destinatario de los productos resulta completamente inútil porque al resolver de manera predecible las situaciones que se exponen en el contenido de los productos, no sólo se proscribe cualquier actividad mental de estos destinatarios, sino que además se impone un modo de percibir, de comprender y de valorar esos contenidos.

Sin voluntad, no hay individuo, esa parece ser la consigna mediante la cual estos frankfurtianos suponen que en la época de la industria cultural no hay individuos autodeterminados y concientes, sino sólo pseudoindividuos despreocupados, alienados y sin posibilidad de elegir libremente el curso de su existencia y mucho menos el de la historia. Estos pseudoindividuos serían entonces una especie de entes pasivos a la espera de hacer el consumo indicado por la industria cultural.
Al lado de esta interpretación de la socialización a partir del poder del relato publicitario, está la que se viene trabajando alrededor de lo que ha sido entendido como la explosión del individualismo contemporáneo y que ha sido trabajada por algunos analistas críticos de la posmodernidad como Gilles Lipovetsky. Para este autor, en la "era del vacío", como comúnmente suele nombrar a la posmodernidad, la socialización, el "amaestramiento social" (Lipovetsky, 2000: 55) se produce por las vías de la seducción, en un mundo rico y abundante en placeres y diversiones.

Desde el punto de vista de este análisis, las épocas de las duras exi-

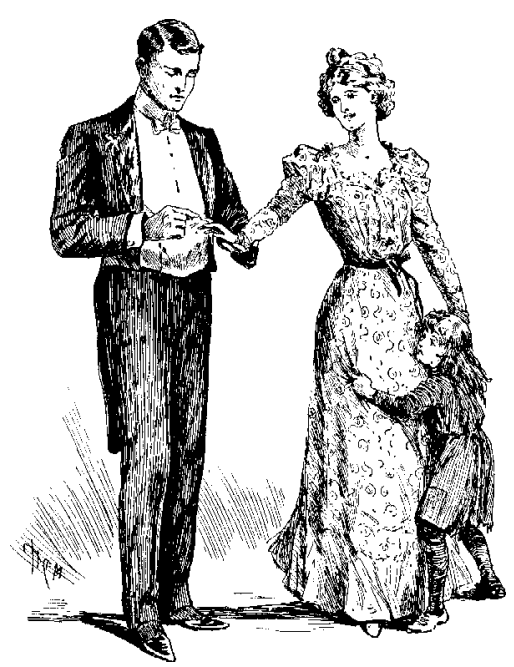


gencias para los individuos han pasado a la historia, la productividad del modelo de desarrollo en algunos países ha hecho posible el olvido de las grandes causas que llevaron, en el pasado, a muchos individuos a sacrificar sus vidas en beneficio de los demás.

A su vez, las graves amenazas que se ciñen sobre la humanidad como las crisis económicas y las ecológicas, el desarrollo de las armas nucleares y químicas, aunadas a la desconfianza que cada vez más generan los gobernantes y políticos, han contribuido a generar no sólo la tendencia al repliegue de los individuos sobre el presente, lo privado y la creciente incertidumbre sobre el futuro, sino también hacia lo que Lipovetsky llama "la desustancialización de la esfera pública” (Lipovetsky, 2000: 36).

Sin embargo, según el planteamiento de este autor, esta es una situación que no comporta tragedia o un sentimiento trágico que afecte a los individuos, pues ni siquiera la ingente cantidad de informaciones que diariamente se suceden unas tras otras en los medios de comunicación es capaz de conmover a los narcisos, encerrados en el caparazón de su privacidad.

Lejos de producir conmoción, la amplia y diversa gama de informaciones, termina produciendo indiferencia entre los individuos que, a instancias del nuevo orden, que funda el capitalismo flexible, habrían aprendido a refugiarse y a utilizar como mecanismo de defensa el confortable ámbito privado, el consumo y la despreocupación por los asuntos públicos (Lipovetsky, 2000: 52).

El repliegue sobre el presente centra las preocupaciones del individuo sobre el cuidado del cuerpo y de su alma y hace emerger lo que se conoce como las revoluciones interiores (Lipovetsky, 2000: 53), que desplazan las preocupaciones por el entorno social y las ponen específi- camente sobre el individuo. En síntesis, la individualización se realiza, desindividualizando, o como sostiene Lipovetsky, desustancializando al individuo (Lipovetsky, 2000: 59) y su subjetividad, puesto que el otro o los otros han dejado de ser una referencia en la constitución de la identidad personal, mientras que el individuo realiza una búsqueda permanente de materiales simbólicos con los cuales poder identificarse, en los productos culturales de los medios de comunicación.

En esta perspectiva, el relato publicitario no es engañoso, simplemente responde a la racionalidad de una época en la que el individuo se asume y asume al mundo de manera desenfadada. Lejos de poder deducir en las funciones que presta al capitalismo, las pretensiones de control ideológico, lo que puede observarse es la intención de contribuir a la generación de una seducción y una provocación continúa hacia el consumo indiferente.

\section{Las condiciones históricas}

Un recorrido por las condiciones históricas que han acompañado el desarrollo de las prácticas de consumo indica que estas condiciones han tenido una fuerte incidencia en el modo como esas prácticas ganaron legitimidad social, a través del desarrollo de la sociedad. En este sentido, es bien conocido la poca buena imagen de la que gozaban estas prácticas, sobre todo en las sociedades que llevaron a cabo la reforma protestante, debido a que se consideraba que todo lo que no fuera indispensable para llevar una vida sobria era considerado como un exceso que podía desviar los fines de la salvación eterna, que exigían el desarrollo de la virtud mediante el desempeño de un trabajo duro, honesto y metódico para poder ser alcanzados (Weber, 1999: 39).

Sin embargo, este tipo de apreciaciones derivadas de la mentalidad productivista, estimulada en los primeros momentos del desarrollo de

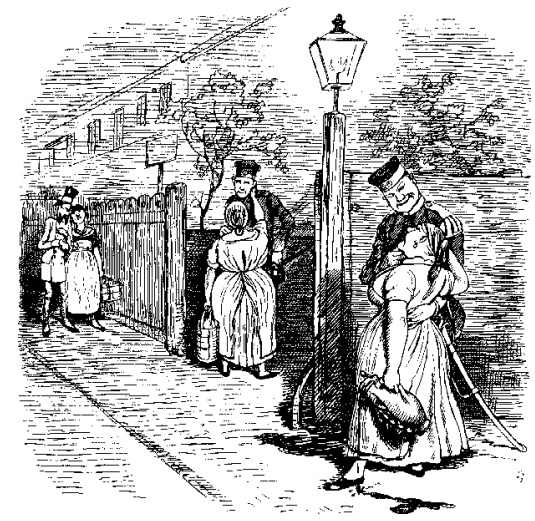

la economía capitalista, no constituyó el único obstáculo para el ejercicio de las prácticas de consumo tal como las conocemos hoy. De hecho, podemos nombrar como su complemento la llamada "Ley de bronce", según la cual el único modo de garantizar la rentabilidad del capital era manteniendo los salarios de los trabajadores en unos bajos niveles, apenas los necesarios para garantizar la supervivencia.

Pero como bien lo ha señalado Juan Cueto, esta fue una situación que se hizo insostenible, incluso para el propio capitalismo, porque no permitía consumir la creciente producción que la sofisticación industrial había logrado, manteniendo grandes existencias de mercancías que la gente no podía comprar, justamente en virtud de los bajos salarios que recibía (Cueto,1985: 16).

La evidencia de la inconveniencia de seguir manteniendo esta "Ley de bronce" la daría la crisis de la bolsa de Nueva York en 1929, cuando debido justamente a una producción excesiva, que no podía ser consumida, se vinieron a bajo los precios de las acciones de las grandes industrias, dejando grandes consecuencias para la economía mundial.

De ahí que los industriales comprendieran que su problema no estaba en producir más, sino en hacer consumir más y que por lo tanto se precisaba una nueva política laboral que permitiera poner más dinero y más 
tiempo al alcance de los trabajadores. Tal política dio origen, como bien lo ha señalado Cueto, a la clase media, que instituiría al consumo como uno de sus más preciados valores y una de sus más importantes prácticas (Cueto, 1985: 17).

Sin lugar a dudas, estas eran prácticas completamente congruentes con las necesidades y los intereses del capitalismo, pero en el fondo lo que importa es que estas prácticas dieron origen a unas mentalidades de consumo desde las cuales se esbozan hoy los intereses de bienestar y hedonismo que persigue la sociedad contemporánea.

Al lado de esa política habría que poner de una parte, el surgimiento de una producción industrial mucho más amplia y diversificada, gracias al desarrollo y la innovación tecnológica y del otro lado, el crecimiento de una industria publicitaria que gracias a la expansión de los medios de comunicación masivos logra llegar cada vez más a un mayor número de consumidores que, desde las más variadas posibilidades expresivas, se identifica y se reconoce en los contenidos difundidos por dichos medios.

\section{Ganancias de la publicidad, pérdidas de la escuela: el balance}

Más que estar evidenciadas en términos cuantitativos, las ganancias de la publicidad y las pérdidas de la escuela se encuentran detalladas en un conjunto de variables cualitativas que se expresan en la capacidad o la incapacidad de una y otra para enfrentarse a los desafíos lanzados por las transformaciones sociales, culturales, cognitivas, económicas y políticas de los últimos años.

Salta a la vista que a pesar de las críticas que siempre han acompañado a la industria publicitaria el balance que puede hacerse a su relación con la sociedad, no deja de arrojar saldos positivos, no sólo por los dividendos económicos que esa relación ha dejado, sino, sobre todo, por el desarrollo de una capacidad para establecer sintonía con los intereses, los fines, los deseos, las necesidades y las expectativas que la sociedad prefigura en sus prácticas de consumo.

Sin embargo, esa capacidad no obtiene resultados por sí sola; de hecho, al lado de ella habría que tener en cuenta el desarrollo de nuevas tecnologías de la comunicación de la imagen que, al decir de Debray (1998), terminan fundando no sólo una nueva época (en la que aunque coexisten distintas formas expresivas, es evidente la centralidad de la imagen), sino también una nueva estructura mental que al liberarse de la linealidad, de la exposición lógica y racional del discurso logra dar paso a complejos entramados, desde donde actualmente los individuos crean y se recrean la cultura.

A su vez, la transformación de la estructura mental ha traído consigo nuevas prácticas de aprendizaje que, aunque no siempre son coherentes con las prácticas de enseñanza que se despliegan en la escuela tradicional ni tampoco con la estructura de su relato ilustrado; si lo son con el diseño de los relatos de algunos productos de la industria cultural, entre los que pueden contarse desde los más sofisticados

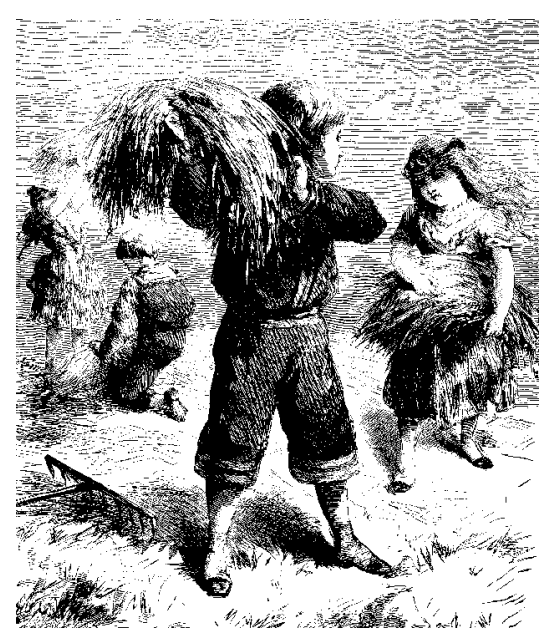

films cinematográficos hasta las más trilladas piezas de la publicidad comercial.

En este sentido, probablemente la clave del éxito de la publicidad no obedezca únicamente a su capacidad para reordenar y renombrar los intereses contenidos en el inconsciente colectivo de sociedad, sino, además, a que en la estructura, episódica, fragmentaria, rítmica y lúdica de su relato están las claves para poder entender por qué y como se producen las compatibilidades entre dicho relato y nueva estructura mental.

Frente a esta situación, desgraciadamente las acciones de la escuela no han sido afortunadas y por el contrario han tenido consecuencias negativas que se manifiestan en un creciente malestar con la escuela, expresado en el tedio, en la falta de atención, de concentración, de interés y en la pérdida de sentido de los contenidos de ésta escuela en la vida cotidiana de los estudiantes.

De este modo, es frecuente que las pérdidas de la escuela se evidencien a través de las innumerables críticas de las cuales viene siendo objeto, desde hace algún tiempo y desde donde frecuentemente se ha dicho que "la escuela tradicional ha apostado todo a un sistema de enseñanza que privilegia la información sobre la experiencia, el saber del educador sobre el saber del educando, dando paso a una educación centrada en la palabra del docente, que tiende a olvidar otros recursos del lenguaje y crea -con las consabidas excepciones- un sistema plagado de sustitutos ${ }^{1}$ carentes de atractivos, tediosos y faltos de recursos expresivos" (Cortés, 1999: 81).

\footnotetext{
${ }^{1}$ Por sustitutos, el autor define un proceso de aprendizaje "basado en percepciones sustitutas, es decir, en modelos o explicaciones elaboradas por otros para mostrarme una realidad $u$ ofrecerme una experiencia que no puedo o no alcanzo a percibir directamente" (Cortés, 1999:80).
} 
Desde esta perspectiva, queda claro que uno de los mayores problemas de la escuela tradicional sigue siendo el exceso de confianza en el poder del relato ilustrado tradicional, como si este por si solo fuera capaz de garantizar la socialización de saberes que esa institución pretende, e incluso dejando por fuera de toda consideración el hecho que, como se dijo anteriormente, no es el relato el que determina las prácticas de socialización que la escuela quiere estimular sino que más bien son estas últimas las que deben marcar la pauta del modo como se deben desarrollar los relatos.

En esta misma dirección se inscriben otra serie de críticas sustentadas en el hecho de que la escuela buscara superar sus problemas adoptando tecnologías que, habiéndose implementado con el propósito de mejorar y facilitar los procesos aprendizaje, no lograron alterar el modelo transmisionista de la enseñanza y en cambio terminaban agudizando la distancia entre el saber y sus destinatarios, debido a que como bien se sabe seguían reiterándose las prácticas y los relatos que de ninguna manera lograban convocar al interés de los estudiantes.

Puede entenderse entonces que en últimas esas tecnologías no pasaran de ser un artificio más de las prácticas de enseñanza, incapaces de enriquecer el proceso de aprendizaje, a pesar de que estas poseen múltiples posibilidades expresivas, gran riqueza en sus lenguajes y amplias potencialidades para adaptar la expresividad de los contenidos a lo que debe ser el propósito fundamental de la escuela: "enseñar a aprender" (Cortés, 1999: 82).

Es evidente que el error ha estado en pretender hacer encajar las tecnologías en el devaluado modelo comunicativo de la transmisión pasando por alto la oportunidad de apostarle a un nuevo modelo en donde el propósito central sea el de establecer sintonía con unas nuevas preocupaciones de los indivi-

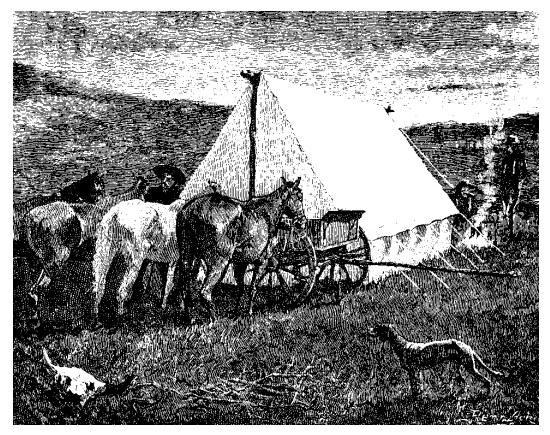

to ilustrado que socializan las prácticas de enseñanza de la escuela obedece a su incapacidad para escuchar y reordenar las hablas inconscientes de la sociedad, para volverlas próximas a los propios intereses de la escuela y de los mismos individuos y para restaurarar sus prácticas y sus relatos, sin perder de vista las nuevas formas de percibir que han impuesto las nuevas tecnologías de comunicación en una época en donde la tendencia es hacia lo no lineal, hacia lo discontinuo.

, pero también con sus nueve formas de percibir, de conocer, de evaluar y de valorar, pues como bien lo ha dicho Jesús Martín-Barbero "la tecnología remite hoy, no a la novedad de unos aparatos, sino a unos nuevos modos de percepción y lenguaje, a unas nuevas sensibilidades y escrituras (Martín- Barbero, 2002: 80).

El desafío para la escuela está entonces en poder convertirse, al igual que la industria publicitaria, en un espacio plenamente significativo para la construcción de aprendizajes de los propios individuos, por donde pasen los intereses y las preocupaciones cotidianas pero también en donde se juegue el futuro individual y colectivo. Probablemente de ninguna otra manera el balance que arroje la relación de la escuela con la sociedad podrá ser positivo. En todo caso, el desafío sigue en pie.

\section{Conclusiones}

Si hoy constatamos el éxito del relato publicitario en la sociedad no es simplemente porque concentre un poder o una potencia que le permita hacer con la sociedad lo que quiera, sino porque ha sido capaz de potenciar las hablas inconscientes, los intereses, los fines y los instintos que se prefiguran en las prácticas del consumo.

De la misma manera, esta hipótesis nos puede llevar a suponer que el cansancio que existe con el rela-
No en otro sentido puede entenderse que con la escuela ha pasado lo mismo que Benjamín observó con respecto a la producción y recepción de la obra de arte clásica, en el sentido en que, mientras ella continuaba exigiendo la distancia, "Ia lejanía" (Benjamín, 1980: 26) con el espectador, el nuevo "sensoriun" (Benjamín, 1980: 23) de la sociedad de masas pedía proximidad, cercanía.

El problema es que la apuesta de las prácticas de enseñanza, así como la de sus relatos, ha sido, muchas veces, por un modelo comunicativo que privilegia la transmi-

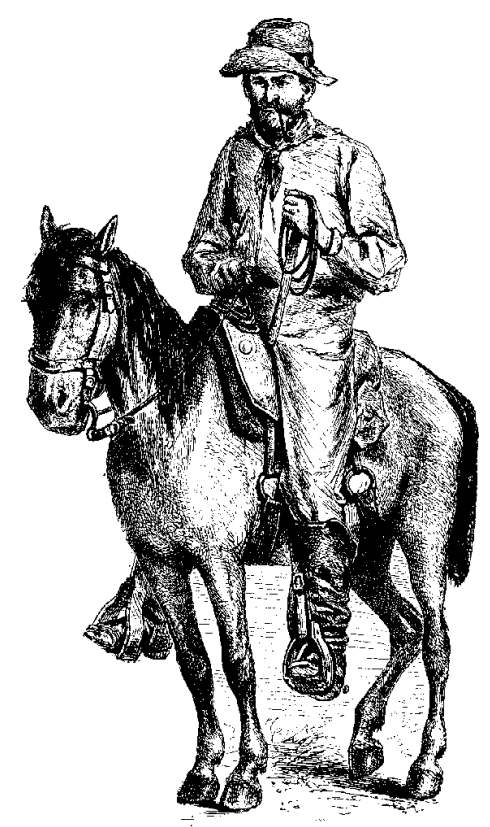




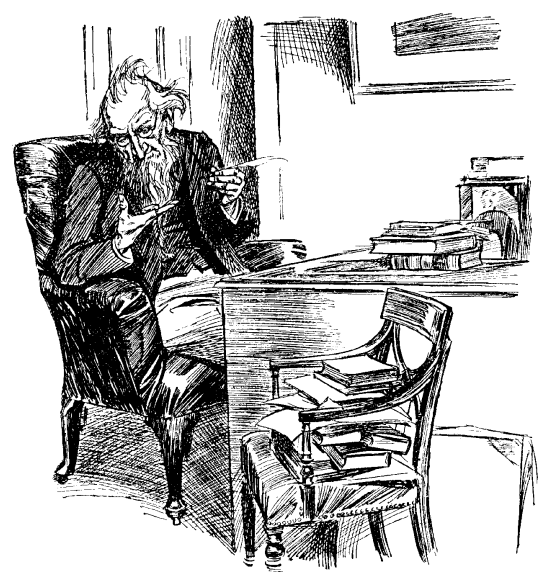

sión simple de unos relatos demasiado distantes de los intereses individuales, olvidándose de la necesidad de instituir un modelo comunicativo que contenga relatos plenamente significativos y cercanos para los individuos.

Para lograr esto la escuela deberá ser capaz, no solo, de ordenar sus relatos en función de la nueva estructura mental, que se ha instituido en un nuevo contexto fuertemente influenciado por las tecnologías, sino también de hacerlos compatibles con los intereses contenidos dentro de esa nueva estructura. Sin embargo, para la escuela debe ser claro que no puede conformarse con la labor de facilitarle a los estudiantes sus procesos de aprendizaje, pues su gran desafío siguen siendo el poder proporcionarles los elementos necesarios para la construcción de una sociedad más solidaria y más justa.

\section{Bibliografía}

Benjamín, Walter. Discursos interrumpidos. Editorial Taurus. Madrid, 1980.

CAlle, Rolando, S.J. "Audiovisualidad y comunicación”. En: Moreno, Marisol y VILLEGAS, Esmeralda. Comunicación, educación y cultura: relaciones, aproximaciones y nuevos retos. Cátedra UNESCO de Comunicación Social, Universidad Javeriana y Fundación Social. Bogotá, 1999.

CoRTÉs, Carlos Eduardo. "Educación, lenguaje y pensamiento visual". En: MoRENO, Marisol y VILLEGAS, Esmeralda. Comunicación, educación y cultura: relaciones, aproximaciones y nuevos retos. Cátedra UNESCO de Comunicación Social, Bogotá, Universidad Javeriana y Fundación Social, 1999.

Cueto, Juan. La sociedad de consumo de masas. Aula Abierta Salvat. Navarra, 1985.

DeBray, Regis. Vida y muerte de la imagen. Barcelona, Ediciones Piados Ibérica S. A., 1998.
EguizÁBAL, Raul. "Publicidad y consumo: nuevos valores de la comunicación organizacional”. En: Revista Telos \# 24, diciembre de 1990- febrero de 1991.

Horkheimer, Max y Adorno, Theodor. "La industria Cultural". En: BeLL, Daniel. Industria cultural y sociedad de masas. Caracas, Monteavila Editores, 1992.

LIPOVETSKY, Guilles. La era del vacío: ensayos sobre el individualismo contemporáneo. Barcelona, Anagrama, 2000.

MARTíN-BARBero, Jesús. La educación desde la comunicación. Buenos Aires, Editorial Norma, 2002.

Mattelart, Armand. Geopolítica de la cultura. Bogotá, Ediciones Desde abajo, 2003

PAOLI, Antonio. Comunicación e información. México, Trillas, 2000.

Pérez ToRneo, J. M. "Claves de la publicidad". En: Rodríguez ILLERA, José Luis. Educación y Comunicación. Barcelona, Ediciones Paidos, 1998.

RAMONET, Ignacio. La fábrica de los deseos. Le Monde Diplomatique, abril de 2002. Edición en español.

Simmel, George. Sociología: estudios sobre las formas de socialización. Alianza editorial. Madrid 1997.

Weber, Max. Ética protestante y espíritu del capitalismo. Madrid, Alba libros, 1999.

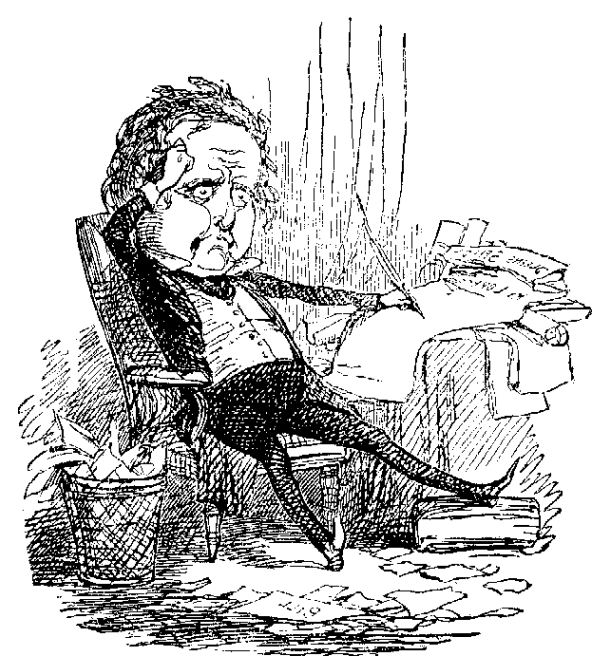

